JOINT HIGHWAY RESEARCH PROJECT

FHWA/IN/JHRP-90/8

Interim Report

AN ACCELERATED TESTING SYSTEM TO

DETERMINE PERCENT CRUSHED

AGGREGATE REQUIREMENTS IN

BITUMINOUS MIXTURES

Thomas D. White

J. M. Albers

John E. Haddock, Sr. 


\section{AN ACCELERATED TESTING SYSTEM TO DETERMINE PERCENT CRUSHED \\ AGGREGATE REQUIREMENTS IN BITUMINOUS MIXTURES}

Interim Report

TO: Harold L. Michael, Director

Joint Highway Research Project

FROM: Thomas D. White, Research Engineer

Joint Highway Research Project
June 11,1990

Profect: C-36-55J

File: $2-12-10$

Attached is the Design Report on the HPR Part II study titled, "An Accelerated Testing System to Determine Percent Crushed Aggregate Requirements in Bituminous Mixtures." This design report is a product of Phase I of the subject study. Subjects addressed in the study are procedures for estimating accelerated structural and rutting damage, refined design and cost estimate and proposed experimental design to determine the minimum crushed aggregate requirements in bituminous mixtures.

Estimates of the time of testing to develop structural and rutting damage have been made. In both cases the projected cycles of loading are within the initial criteria of equaling the damage in 10 years of interstate type traffic with one year of continuous operation. Design of the Accelerated Testing System (ATS) was constrained to achieve the initial criteria. In fact, the analysis suggests that the ATS, as designed, will easily achieve the stated goal. Detalled material and labor costs by subsystem as well as by specific item are presented based on the proposed design. An experimental design has been developed with input from INDOT, Purdue and aggregate industry representatives.

This report is forwarded to INDOT and FHWA in fulfillment of the Phase I objectives of the study.

\section{Respectively submitted,}

T. D. White

Research Engineer

$\mathrm{TDW} / \mathrm{rrp}$

\author{
cc: A.G. Altschaef $f 1$ \\ J.M. Bell \\ W.F. Chen \\ W.L. Dolch \\ R.L. Eskew \\ J.D. Fricker \\ M.K. Hunter
}

\author{
R.K. Howden \\ J.P. Isenbarger \\ K.M. Mellinger \\ R.D. Miles \\ P.L. Owens \\ B.K. Partridge \\ G.T. Satterly
}

C.F. Scholer
K.C. Sinha
J.R. Skinner
C.A. Venable
L.E. Wood
T.D. White 
Interim Report

AN ACCELERATED TESTING SYSTEM TO

DETERMINING PERCENT CRUSHED AGGREGATE REQUIREMENTS IN

BITUMINOUS MIXTURES

by

T. D. White

J. M. Albers

and

John E. Haddock, Sr.

Joint Highway Research Project

Project No.: C-36-55J

File No.: 2-12-10

Prepared for an Investigation

Conducted by the

Joint Highway Research Profect

Engineering Experiment Station

Purdue University

in cooperation with the

Indiana Department of Highways

and the

U.S. Department of Transportation

Federal Highway Administration

The opinion, findings and conclusions expressed in this publication are those of the authors and not necessarily those of the Federal Highway Administration.

Purdue University

West Lafayette, Indiana

May 1990 
TECHNICAL REPORT STANDARD TITLE PAGE

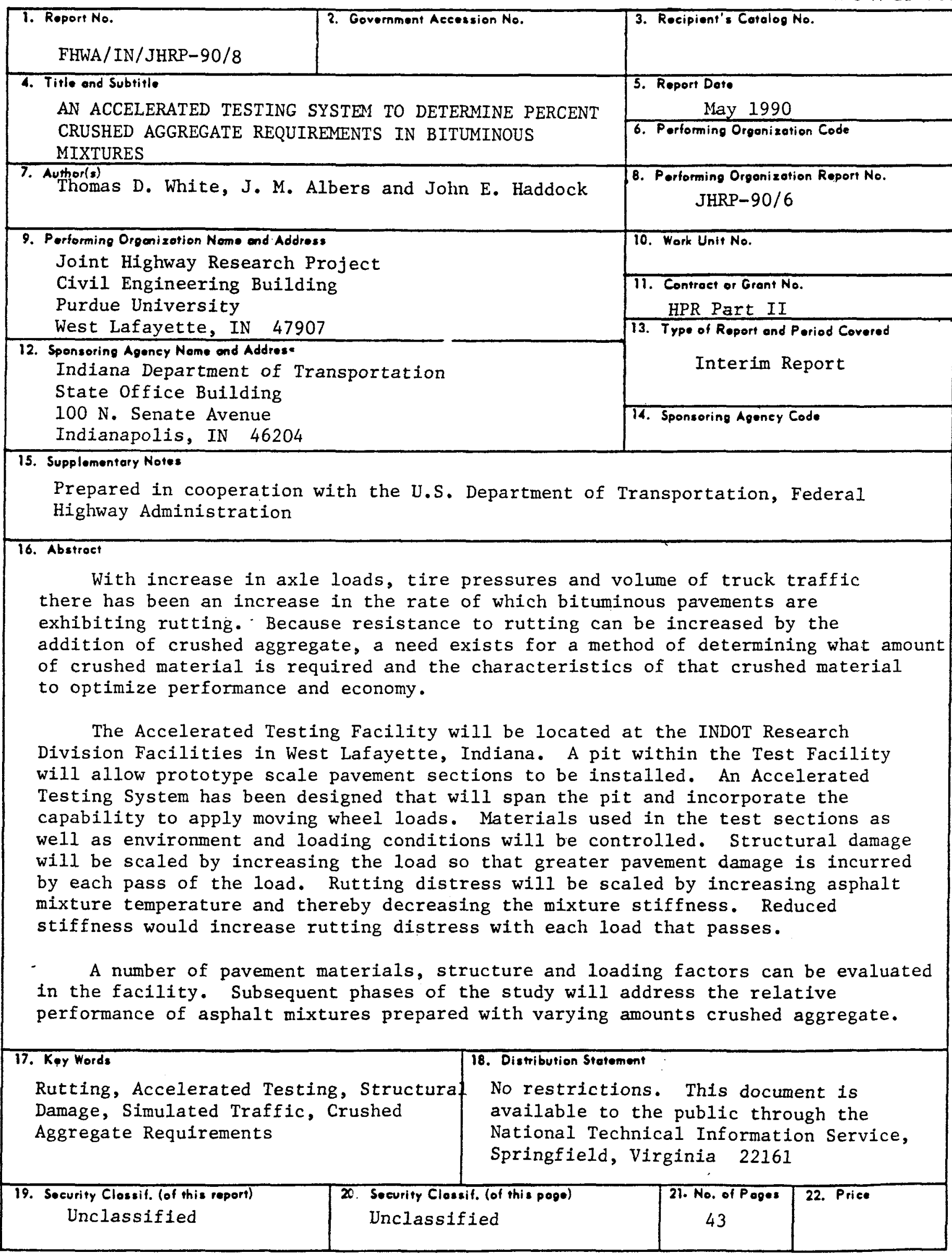




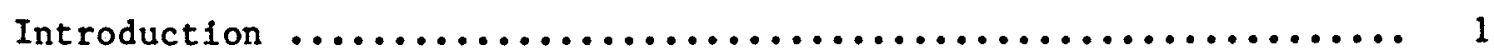

Literature Review $\ldots \ldots \ldots \ldots \ldots \ldots \ldots \ldots \ldots \ldots \ldots \ldots \ldots \ldots \ldots \ldots \ldots \ldots$

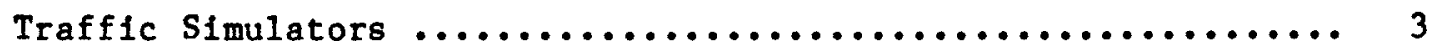

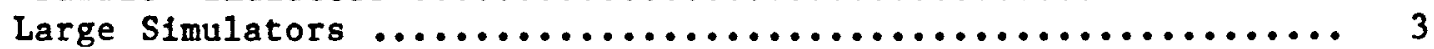

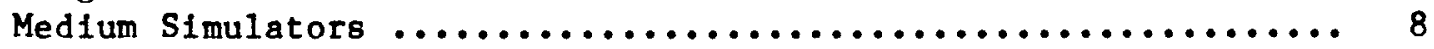

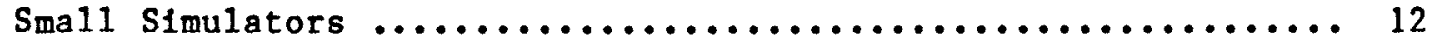

Accelerated Rutting Due to Decreased Mixture Stiffness ........ 14

Minimum Crushed Aggregate Content ..................... 15

Accelerated Damage Due to Load $\ldots \ldots \ldots \ldots \ldots \ldots \ldots \ldots \ldots \ldots \ldots \ldots$

Estimate of Rutting Damage $\ldots \ldots \ldots \ldots \ldots \ldots \ldots \ldots \ldots \ldots \ldots \ldots \ldots$

Design of Accelerated Testing Systems $\ldots \ldots \ldots \ldots \ldots \ldots \ldots \ldots \ldots \ldots$

Experimental Design Planning $\ldots \ldots \ldots \ldots \ldots \ldots \ldots \ldots \ldots \ldots \ldots \ldots \ldots \ldots$

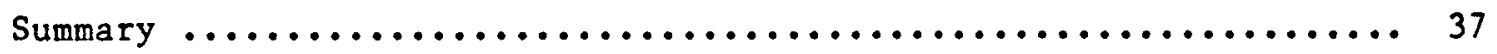

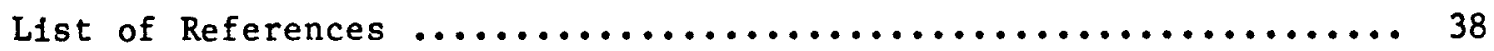

Appendix A: Estimated Costs of Accelerated Testing System ...... 42 
Table
1 Time Needed to Compress Ten Years of Traffic into One

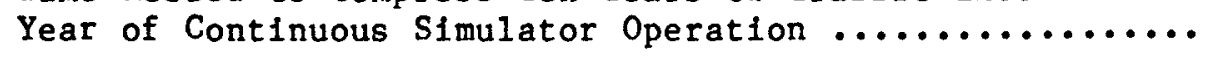

\section{LIST OF FIGURES}

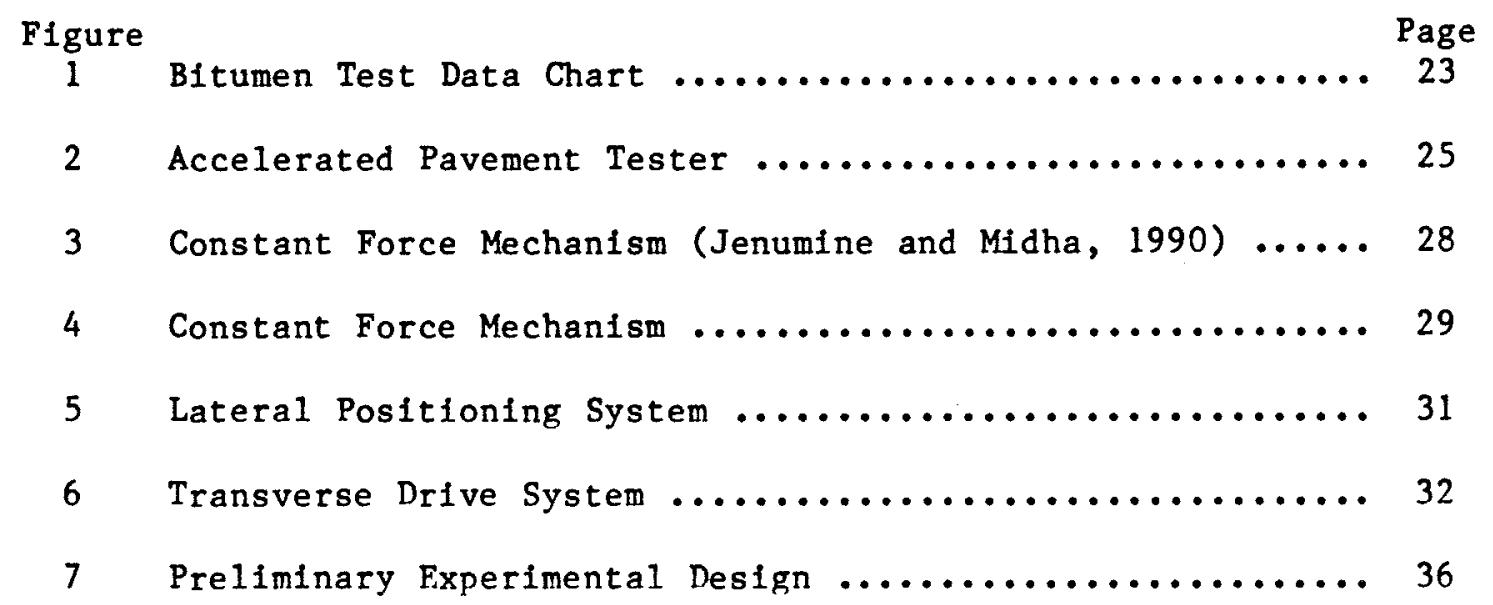


An Accelerated Testing System to

Determine Percent Crushed Aggregate Requirements in
Bituminous Mixtures

by

Thomas D. White

J. M. Albers and

John E. Haddock, Sr.

\section{Introduction}

With Increase in axle loads, tire pressures and volume of truck traffic there has been an increase in the rate of which bituminous pavements are exhibiting rutting. The resistance to rutting of conventional bituminous mixture depends on a number of factors related to its constituents. One important constituent is the nature and the amount of crushed aggregate. However, it is important to consider economy and the use of local materials. Local materials may mean sand and gravels which are avallable in many parts of Indiana. Economy may come from the lower cost or shorter hauling distance. The desire for economy and use of local materials is offset by the need to insure that bituminous mixtures used in surfacing the highway pavements in Indiana will provide the desired performance. Because resistance to rutting can be increased by the addition of crushed aggregate, a need exists for a method of determining what amount of crushed material is required and the characteristics of that crushed material to optimize performance and economy.

Tests on small, laboratory size specimens do not reliably scale to performance of prototype pavements. Prototype pavement test sections can solve the problem of scale, however, differences in performance may take many years to develop. An alternative testing procedure is to consider testing a small section of pavement with prototype loads. Such testing may utilize techniques 
to reduce the time for performance differences to develop. Structural damage may be scaled by increasing the load so that greater pavement damage is incurred by each pass of the load. Rutting distress may be scaled by increasIng asphalt mixture temperature and thereby decreasing the mixture stiffness. Reduced stiffness would increase rutting distress with each load that passes.

A "Traffic Simulator" or accelerated testing system (ATS) has been designed with which simulated truck traffic can be applied to a small section of pavement. Materials used in the test sections as well as environment and loading conditions can be controlled. A number of pavement materials, structure and loading factors can be evaluated in the facility. The current study w111 address the relative performance of asphalt mixtures prepared with varying amounts crushed aggregate.

Other types of paving materials such as modifiers can also be evaluated with the ATS. Laboratory results indicate that such materials increase bituminous mixture high temperature stability without reducing their performance at low temperatures. In fact, in some cases there is a potential for these materials to provide even better low temperature properties while maintaining high temperature stability. By selecting the proper scale of the ATS and developing an adequate design, structural capacity of pavement systems can also be evaluated.

The Accelerated Testing Fac1lity will be located at the INDOT Research Division Facilities in West Lafayette, Indiana. A pit within the Test Facil1ty w11l allow prototype scale pavement sections to be installed. The ATS w11l span the pit and incorporate the capability to apply moving wheel loads. Design and characteristics of the ATS and its application to the study of 
pavement structural and material factors are discussed in the following sections. Plans are also presented for the study of the minimum crushed aggregate requirements in bituminous mixtures.

\section{Literature Review}

\section{Traffic Simulators}

Over the years, a number of different designs of "traffic simulators" have been used in pavement research. Use of a traffic simulator is the direct result of the researchers need for more timely and accurate data. The simulators allow for data to be obtained under controlled conditions. At the same time the data is more realistic. Types of simulators can be grouped according to size ( $1 . e$. large, medium, and small).

Large Simulators

The large simulator class generally includes simulators which are outdoors and if indoors, require more than an average size laboratory for their operation. These simulators range all the way from the test tracks at the United States Army Corps of Engineers Waterways Experiment Station to the circular test track at Washington State University.

One of the earliest applications of simulated traffic under controlled. conditions in pavement research was conducted by the US Army Corps of Engineers (USAE) at the Waterways Experiment Station (WES). In traffic tests that developed the original Marshall bituminous mix design criteria (Department of the Army Technical Memorandum No. 3-254, 1948), wheel loads of 15,000; 37,000 and 60,000 1bs with tire and contact pressures shown below were used to apply accelerated traffic in amounts up to 3,500 coverages. A coverage is 
defined as the number of passes to cover the full width of a test lane with a given width tire. In the final analysis, much of the comparison of the mixture propertles was made at 500 and 1,500 coverages of the applied traffic.

$\begin{array}{ccccc}\begin{array}{c}\text { Gross } \\ \text { Loads-Lb }\end{array} & \begin{array}{c}\text { Load per } \\ \text { Tire-Lb }\end{array} & \begin{array}{c}\text { Inflation } \\ \text { Pressure-PSI }\end{array} & \begin{array}{c}\text { Gross Contact } \\ \text { Pressure-PSI }\end{array} & \begin{array}{c}\text { Net Contact } \\ \text { Pressure-PSI }\end{array} \\ 15,000 & 15,000 & 50 & 54.3 & 105.6 \\ 37,000 & 37,000 & 110 & 98.7 & 146.2 \\ 60,000 & 30,000 & 110 & 91.3 & 139.2\end{array}$

Earlier laboratory tests included samples with asphalt contents that bracketed the optimum asphalt content as determined by the peak of the stabil1ty curve. Subsequent experience with test sections at Marletta, GA indicated that optimum selected at the peak of the stability curve would be overrich. Consequent1y, the test sections at WES were constructed at optimum and 10 and 20 percent lean of optimum. The traffic tests were planned and conducted not only to compare paving mixtures with variable properties and identify traffic related optimum asphalt content ranges, but also to determine minimum thickness of asphalt surfacing over low and medium quality bases.

In tests of base courses conducted by Maxwe11, et al. (1962), three different vehicle load carts were used. The three vehicles were configured and loaded to app1y a $10,00025,000$ and $50,000 \mathrm{lb}$. single-wheel load, respectively.

The $10,000 \mathrm{lb}$. vehicle consisted of a loaded axle powered by the front half of a four wheel drive truck. A type I 34:00-9.9, aircraft tire was used inflated to $100 \mathrm{ps}$. The 25,000 and $50,000 \mathrm{1b}$. load carts were pulled by a 
tractor on which were mounted a 56:00-16, type I, and a 25:00-28, type III, aircraft tire, respectively. Both tires were inflated to 100 psi.

In these tests, the pavement test sections were constructed in an open ended aircraft hanger and therefore were isolated from rainfall. The test sections were 12 feet wide by 150 feet long. Traffic was applied on three four feet wide lanes. These lanes were trafflcked such that each lane was loaded with specific loads a specified number of times. The purpose of the test was to evaluate base courses using various loads and tire pressures. The base course itself consisted of a graded crushed limestone. After compaction and prior to traffic, a bituminous seal coat was applied.

The two primary conclusions of the above study were: (1) Occasional traffic overloads applied to pavement does in fact shorten the life of the pavement even if the load does not cause immediate and drastic damage; and (2) the number of passes of basic traffic needed to equal one pass of an overload varys directly with the thickness and condition of the pavement and base course.

A similar test was conducted at WES and reported by Ledbetter, et al. (1972) to determine the effects of "fumbo fets" on pavement performance. Five test sections for this experiment were built in an area 60 feet wide and 300 feet long. Each pavement section was trafficked in a previously specified manner. Four different test vehicles were used. One of the vehicles used was a cart configured to represent one-half the main gear of a C5A military transport alrcraft. This twelve wheel assembly was loaded so that each wheel carried a $30,000 \mathrm{lb}$. load. The tires were inflated to $100 \mathrm{psi}$. A second cart was configured to represent the twin-tandem gear of the Boeing 747 . In this 
test, the cart was loaded at $60,0001 \mathrm{~h}$. per wheel (1,000,000 1b. loading condition for the entire aircraft - an overload condition). The tires were inflated to a pressure of $225 \mathrm{psi}$. Two other carts were configured for a $30,000 \mathrm{lb}$. and a 50,000 1b. single-wheel load, respectively. The former had a tire pressure of $100 \mathrm{psi}$, and the latter a pressure of $165 \mathrm{psi}$.

The major conclusions reached in this report were that the higher repet1tions of these heavy, many-wheeled vehicles was more favorable than previous theory had Indicated, and the measured stress and deflection are not well predicted by sophisticated linear theoretical treatments (Ledbetter, et al., 1972).

A test track used by Paterson (1972) consisted of an octagonal annulus located outdoors at the University of Canterbury in Christchurch, New Zealand. The track had a mean diameter of 60 feet and the actual track was four feet wide. Traffic was applied with two sets of dual tires at elther end of an arm extending across the diameter of the track. The center pivot was eccentrically located so that the wheels tracked a path which included wander. Concrete ballast was used for loads ranging from 3000 lbs. to 9000 lbs. The apparatus was capable of maintaining a constant speed of $12 \mathrm{mph}$. Power was supplied by an electric motor on one set of wheels and the other wheels were free turning. The tires used were $9.00 \times 20 \times 12$ ply.

For a study of transient and permanent deformations in asphaltic concrete pavements, Paterson used bituminous mixture placed on 11 inch thick concrete slabs. Within these slabs, heating elements were placed to keep the pavement within 2 degrees of the desired temperature. As a result, the response of bituminous mixtures at different temperatures and loads could be studied. 
Use of a circular test track at Washington State University was reported by Kingham and Kallas (1972), and Mahoney and Terrel (1982). This traffic simulator has three sets of dual wheels each connected to the center by a radial arm. Load is applied through weight of the structure as well as a water tank. Each of the inside wheels is driven by an electric motor while the three outside wheels turn freely. An eccentric mechanism allows for wander. The test track diameter is 84 feet and the wander is spread over a 4 feet width.

Kingham and Kallas (1972) compared three pavement bases, a bituminous concrete base, a sand bituminous base, and a crushed stone base. The purpose of the study was to relatively evaluate base performance under simulated inservice conditions, as well as to see if laboratory tests could predict in situ pavement performance. Their conclusion was that the laboratory experiments did predict fairly well the actual performance of the pavement under the action of the traffic simulator.

Mahoney and Terrel used the Washington State simulator to study the performance of three bituminous mixtures. One mixture was dense graded and the other two contained a sulfur additive. These results were also compared with laboratory tests.

In 1977, Sharma, et al. reported on work at the Pennsylvania State Unfversity Test Track to correlate actual pavement performance and response with that predicted by the FHWA program VESYS IIM. The Penn State Test Track is a one mile oval. One end of the oval has a $-1 \%$ grade and a design speed of $50 \mathrm{mph}$. The other smaller end of the oval has a $+1 \%$ grade and a design speed of $35 \mathrm{mph}$. Tangent sections are on $0.3 \%$ grades and are constructed so that 
one is totally in cut and the other totally in f111. Traffic was applled by a standard truck tractor pulling trailers loaded with ballast (metal ingots). By changing the size, amount, and location of the ballast, the axle loads could be varied. The study concluded that the program did indeed give reasonable results. However, it was felt that local data would be needed for calibration to local conditions.

In Switzerland, Scaziga (1982) used a traffic slmulator to re-evaluate the design procedures for flexible pavements. The simulator has three radial arms each having dual truck tires (11.00-20) loaded to 5 tons. The tires track around a ring having an average radius of 16 meters. Each wheel assembly is powered by an electric motor. The pavement structure was constructed in a concrete pit two meters deep. Scazziga concluded that the AASHTO Interim Guide Method (1972) provided for the thickest and most conservative designs.

A large circular traffic simulator is also located at the Laboratoire Central des Ponts et Chaussees (Public Works Research Laboratory) in Nantes. This track has an outside diameter of 41 meters and is 6 meters wide. Four arms, each 14 meters long, rotate around the circular facility. At the end of each arm is a half axle which can slide in and out on the arm to allow for trafficking at different radii as well as providing for wander. The unit is driven by four slow-speed hydraulic motors situated at the center turret. Research was conducted with the simulator to determine if test results would be realistic. It was the conclusion of the researchers that the traffic simulator provided realistic data (Autret, et al., 1987).

\section{Medium Simulators}

Although most medium size simulators are outside where the test pavements 
are exposed to the elements, the simulators themselves as well as the test sections are smaller than those in the large group.

In 1967, Gusfeldt and Dempwolff reported on the use of a traffic simulator for pavement research in Germany. The simulator consisted of two parallel steel girders which supported a dolly between them. A test wheel was mounted on the dolly. The wheel had a diameter of $100 \mathrm{~cm}$ and was usually inflated to a pressure of $5 \mathrm{kp} / \mathrm{cm}^{2}$. An electric motor powered the load wheel via a drive cable and could attain a top speed of $50 \mathrm{~km} / \mathrm{h}$. Load was provided by means of a pneumatic system which used the two girders as reaction beams. The system was capable of providing a load of between 0.4 and 2.0 tons. Test sections to which traffic was applied measured $10 \times 10$ meters with 30 meters on either end to provide for the acceleration and deceleration of the dolly. The traffic simulator described can easily be disassembled to allow normal construction techniques to be used for test sections.

Pavement stresses and strains were determined using the traffic simulator. It was concluded that the results obtained were in good agreement with the results predicted by theory. This agreement warranted further testing using the simulator.

In additional work, Dempwolff and Sommer (1972) measured radial strains (longltudinal and transverse) and vertical strains in a bituminous layer along with vertical stresses in the unbound base and soll layers. Using a singlewheel $(9 \times 20 \times 10 \mathrm{ply})$ inflated to a pressure of 5 bars, results were obtained on the effects of temperature, loading time, bitumen grade, and bituminous $\mathrm{mix}$ properties. 
Research by Brown and Pappin (1982) made use of a "Pavement Test Fac111ty." This simulator was configured with one wheel with a diameter of $560 \mathrm{~mm}$ which could be loaded up to $15 \mathrm{kN}$. Load was applied by means of a hydraulfc ram which reacts against a steel girder spanning the test section parallel to the direction of wheel travel. The trafficked test section was 4.8 meters long, 2.4 meters wide, and 1.5 meters deep. In their work, the simulator was used to continue the development of analytical procedures for predicting pavement performance. They concluded that the simulator was a valuable tool in validating analytical design methods.

The "Heavy Vehicle Simulator" (HVS) used in South Africa is described by van Vuuren (1972). Mounted on a wheeled frame, the HVS can be transported under its own power to conduct in situ pavement traffic tests. Once at a test site, the trafficking wheel is mounted for testing. The load may be applied to tires ranging in size from a $5.20 \times 10$ to a $14.00 \times 20$. Load is applled by hydraulically reacting against the frame and can range from 20 to $80 \mathrm{kN}$. A hydraulic motor with a chain drive provides power. Traffic an be applied in both directions at a speed of $10 \mathrm{~km} / \mathrm{h}$. The tire can track in an area 6 meters long and 1 meter wide. Lateral wander of the tire is allowed for with the system.

A number of South African researchers have used the HVS. Freeme, et al. (1982) reported on the use of the HVS in the development of a mechanistic pavement design procedure in South Africa. Viljoen, et al. (1987) used the HVS to test the resistance to crackings of conventional and innovative overlays.

Additionally, use of the HVS was reported by Hugo, et al. (undated) for 
research aimed at investigating the influence of low temperature and aging on premature cracking. For this study, special equipment was added to the HVS. The special equipment allowed for cooling as well as accelerating pavement aging. A cooling chamber was constructed around the load tire large enough to cool 2.5 meters of the 6 meter test section. Aging was stimulated by using Infra-red and black lights in sequence. A $2 \times 2$ meter section of the test pavement could be aged.

The conclusions of this study were that low temperatures do initiate early cracking in pavements and that cracking in aged pavements is a complex phenomena.

Ferrefra, et al. (1987) used the HVS in investigations into the performance of recycled materials in pavements. In this study, test pavements consisted of two $50 \mathrm{~mm}$ base layers each containing $70 \%$ reclaimed material and a new $40 \mathrm{~mm}$ wearing course. Applied loads ranged from 70 to $100 \mathrm{kN}$. The researchers concluded that the behavior of recycled material was a function of the support provided by the subbase layers. If support was adequate, the recycled material performed according to design. It was further determined that if cracking did occur, the pavement life could be extended by preventing water infiltration.

As an alternative to the HVS, researchers in Australia developed the. "Accelerated Loading Facility" (ALF). The specifics of this simulator were presented by Radar (1987) in a study designed to set up and test pavement monitoring systems. This study was also used to design a system for containing monftoring pavement structural performance. Both of these goals were fulfilled by using ALF. The ALF simulator makes use of a steel support frame. 
Ballast is used to provide load which may be varied from 4 to 8 tons in 1 ton increments. The wheel assembly is accelerated to a speed of $20 \mathrm{~km} / \mathrm{h}$ by rolling down a ramp and across a 12 meter test section. Deceleration occurs when the tires run up a second ramp. The tires return to the starting point by rolling along a steel plate located on the underside of the upper support beam. This allows the wheels to continue rotating in the same direction at all times. Wander is provided for by moving the entire frame transversely. By addition of wheels attached to the frame, ALF becomes mobile so that in situ pavement can be trafficked.

The Federal Highway Administration (FHWA) has purchased the design and built an ALF system which is currently in operation at the FHWA TurnerFairbanks Research Laboratory in McLean, Virginia. A number of interesting studies are currently underway using this equipment.

Small Simulators

Small traffic simulators are for the most part installed in laboratories. They are viewed as a laboratory tool which can simulate some of the effects of traffic. They are not, generally speaking, as effective as the larger simulators that have previously been described. One limitation of the small traffic simulators is that the pavements tested cannot be placed by normal construction methods. Results of trafficking tests are therefore limited.

One of the small laboratory simulators that has been used effectively is the "Rolling Wheel Machine," or as it is sometimes called, the "Road Test Machine" built and used by the Royal Dutch/Shell Group. This simulator has a 3 meter clrcular track where the test sections are constructed between two concrete walls. A beam with a wheel at either end is attached to a center 
pivot. The wheels rotate around the pivot. Speed can be varied over a range up to $18-20 \mathrm{~km} / \mathrm{h}$. Loads between 100 and $2000 \mathrm{~kg}$ are applied hydraulically.

Bazin and Saunier (1967) reported on use of the Royal Dutch/Shell simulator in research studying the properties of bituminous materials. Klomp and Niesman (1967) presented work using the same simulator to examine strains in flexible pavement at different speeds. They conclude from their tests that the tensile strain was reduced $40 \%$ when speed was 1 creased from $1 \mathrm{~km} / \mathrm{h}$ to 16 $\mathrm{km} / \mathrm{h}$.

Hofstra and Valkering (1972) and Hofstra and Klomp (1972) also conducted research with the Royal Dutch/Shell simulator. The first research was done to determine if elastic theory represented the behavior of flexible pavement under the action of moving wheels. Their findings were that the elastic theory did agree well with the data obtained in the laboratory. The second study was designed to examine pavement rutting. Temperature effects on rutting was part of the study. Data showed that rutting over a temperature range of $20-60^{\circ} \mathrm{C}$ was much greater than the increase in rutting predicted by elastic theory. Both of these research efforts required that the simulator apparatus include some faclity for heating the pavement. Heating was accomplished by the addition of thermal hoods which were mounted on the beam. The thermal hoods rotate with but are slightly ahead of each of the wheels.

A simulator was built at the University of Illinols Urbana-Champaign (UT) in conjuction with testing on several sections continuing pozzolanic materials. Barenberg (1967) describes the simulator. The vI simulator is described as a "Loading Frame" weighing 3500 lbs. With ballast the total weight could be increased to 6400 1bs. Th1s frame rotated about a center pivot. A wheel 
was attached to either end. Top rotation speed was $25 \mathrm{rpm}$. Wander was included in the test by means of small oscillations of the simulator.

Eisnmann and Hilmer presented a paper describing the use of a "Test Facility" to study the influence of wheel loading and inflation pressure on rutting of pavements in Germany. The facility used was a tire pair configured as either two separate tires or one set of dual tires. Materials to be tested were placed in a steel box. A rubber mat of known elastic properties was used to simulated the foundation support. The rolling speed of the wheels was 1 $\mathrm{km} / \mathrm{h}$ with a loading frequency of about 2.5 seconds. This slower speed caused faster rutting of the material than would normally occur. The report concluded that wheel load, inflation pressure, average contact pressure, and tire arrangement have an important effect on rutting.

Accelerated Rutting Due to Decreased Mixture Stiffness

In order to study rutting and the minimum crushed aggregate requirements, test pavement rutting will be accelerated. One way this can be accomplished is by increasing the bituminous mixture temperature and thereby decreasing its stiffness. Since bituminous material is a viscoelastic material, the theory behind this method is simplified.

Papazian (1962) presented work on the response of viscoelastic material In the frequency domain. Two pertinent conclusions were reached in the study. First, the asphalt concrete shows a higher degree of elasticity with a higher rate of loading. In fact, Papazian concludes that at a very high loading frequency, the real part of the elastic modulus approaches a value of instantaneous elasticity. Secondly, the permanent deformation is both a function of number of load applications and duration of loading. The longer the duration 
or the greater the number of loads, the greater will be the permanent deformation.

Hofstra and Klomp (1972) in their work with the Royal Dutch/Shell simulator indicate that with an increasing number of repetitions, the permanent deformation per pass decreases. Their study also included studies on the effects of temperature on deformation. Deformations are related to the binder viscosity. Therefore, the viscosity is merely another measure of the stiffness of the mix. A stiffer material is more viscous.

Minimum Crushed Aggregate Content

One aspect of bituminous mixtures which will be addressed in this study is the minimum crushed aggregate content. Since crushed aggregate is more expensive than pit run aggregate, money can be saved by using as much pit run material as is feasibly. This, however, can create problems if not enough crushed material is used. One problem which can arise in this situation is rutting.

Several research efforts have been directed toward crushed aggregate requirements in asphalt mixtures. One example is a study done in 1987 by Regan at the USAE Waterways Experiment Station. His research examined the role of high pressure (350-400 psi) alrcraft tires in rutting. Crushed 1imestone aggregate blends were used in combination with three different binders. Asphalt paving grades of $A C 20, A C 40$, and a modifled $A C 20$ were used in Marshall specimens prepared using 75 blows per face with a manual handhammer. Additional samples were prepared using a gyratory compactor. Laboratory tests conducted in the study included indirect tensile (static and dynamic), direct shear tests, accelerated aging tests, and unconfined creep tests. The study 
found that current heavy-duty design methods were adequate. However, it was concluded that more compaction was needed to avoid rutting and densification.

A laboratory study conducted by Akhter and Witczak (1985) compared mixes of crushed stone, gravel, slag, and sand. Using the amassed data, a simulation was done on pavement models for fatigue and rutting. A regression equation was developed to predict these performance characteristics.

In 1985, Hicks, et al. reported on a study for the Alaska Transportation Department to determine an approach for using crushed aggregate in airfield and highway pavements. They used laboratory analysis to determine the effects of fracture and gradation on both aggregate bases and asphalt concrete.

Eppensteiner, et al. (1979) conducted a study to relate laboratory tests on bituminous pavements to actual performance. The experiment involved constructing 44 test sections using 20 different aggregates and then observing the pavements performance over a five year perlod. An attempt was made to develop a numerical relationship between laboratory performance and in situ performance but was unsuccessful.

In a report by Kraemer in 1966 , recommendations were made that $70 \%$ crushed stone and $30 \%$ rounded-stone are preferable for bituminous mixtures because maximum compaction could be obtained which corresponded to maximum stability.

\section{Accelerated Damage Due to Load}

Pavement damage can be accelerated by increasing loads. For example, the effect of increasing an $18 \mathrm{kip}$ axle load ( $9 \mathrm{klps}$ per half-axle) can be estimated using the AASHTO load equivalency factors (Yoder \& Witczak, pp. 
147-150). With increased load the damage per pass is multiplied. As a result, the time to achleve a total amount of damage can be reduced.

The AASHTO load equivalences factors (LER) were derived to relate the loss in serviceability of the pavement caused by a given vehicle to the loss In serviceability caused by a standard vehicle (18 kip axle). Using the AASHTO LEFs (1bid pp. 164-167) and given the number of load repetitions of the standard vehicle to cause a terminal serviceability, the number of repetitions of the given vehicle to reach the terminal serviceability can be determined. Using the AASHTO LEFs a set of relations can be developed for the number of load repetitions of the half-axle load of the ATS to reach a terminal serviceability. To determine the required load needed on the ATS, the number of repetitions of the standard load to fallure can be equated to the number of load repetitions of the ATS which can be applied in the given time frame. These two values then fix the load which must be applied by the ATS to obtain an equivalent loss in serviceability.

Based on calculations using reasonable structural capacity (10 inch rigid $s l a b$ and $S N=6(C B R=3)$ for flexible pavement), $P_{t}=2.0$ and assuming ten years of highway traffic to be 35 million $18 \mathrm{kip}$ equivalent axle loads, curves have been prepared for both rigid and flexible pavements. Using these curves, the load which must be applied by the ATS can be determined.

Since many different loads and number of load repetitions can be profected the real limiting factor becomes time. How much time should be spent trafficking the pavement? At the outset of the project it was stated that the desirable and realistic goal was to compress 10 years of highway traffic into 1 year or less of simulated traffic. The limiting time period therefore 
becomes 1 year. Assuming that there are approximately 200 working days in the year and that the ATS will have down time for repalr, cleaning and maintenance, a reasonable assumption can be made of 120 days of operation per year ( $60 \%$ of 200 days).

To evaluate speed and load effect a matrix involving different loads, speeds, and time is shown in Table 1. As may be seen for each of the loads there is a significant reduction in the time requirements if the ATS speed is Increased from 3 to $7 \mathrm{mph}$. Furthermore, the time for the profected number of load repetitions is substantlally reduced if the ATS load is increased from 15 to 20 kips.

Values in Table 1 were calculated using reasonable assumptions. The distance the wheel would travel was assumed to be $22 \mathrm{feet}$. A width of 20 feet is planned for the test pit and an additional foot was added at each end for extra distance to stop, reverse, and restart the whee1. It was further assumed that the time needed to stop, reverse, and restart the wheel is negligible. This assumption seems valid in light of the fact that the speeds involved are all below $10 \mathrm{mph}$ and that the simulator is loaded by springs rather than ballast.

\section{Estimate of Rutting Damage}

In addition to traffic, speed and temperature are two major factors expected to contribute to compression of time of testing for rutting damage to develop. A reduction of speed would increase the loading time and the viscous component of deformation. An Increase in temperature would have the same effect. The magnitude of the speed and temperature effect can be estimated using the Shell method (Classen, et a1., 1977). 


\begin{tabular}{|c|c|c|c|c|}
\hline & & $\begin{array}{l}\text { SPEED } \\
\text { (МPH) }\end{array}$ & GOURS & DATS \\
\hline \multirow{9}{*}{ 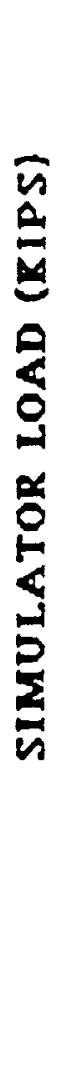 } & \multirow{3}{*}{15} & 3 & 4,861 & 203 \\
\hline & & 5 & 2,917 & 122 \\
\hline & & 7 & 2,083 & 87 \\
\hline & \multirow{3}{*}{17.5} & 3 & 2,778 & 116 \\
\hline & & 5 & 1,667 & 69 \\
\hline & & 7 & 1,190 & 50 \\
\hline & \multirow{3}{*}{20} & 3 & 1,528 & 64 \\
\hline & & 5 & 917 & 38 \\
\hline & & 7 & 655 & 27 \\
\hline
\end{tabular}

TABLE 1. Time needed to compress ten years $\alpha$ traffic. into one year $\alpha$ continous simulator operation. 
Temperature, loading time and traffic are accounted for in the relation:

$$
\begin{aligned}
S_{b 1 t, v i s c}=\frac{3}{t_{w} \sum\left(\frac{N}{\pi}\right)_{T}} \\
S_{b i t, v i s c}=\text { Viscous component of bitumen stiffness } \\
t_{w}=\text { Time of one wheel pass } \\
N=\text { Number of wheel passes } \\
\eta=\text { Viscosity } \\
T=\text { Test temperature. }
\end{aligned}
$$

In the denominator of the right hand side of the equation, the term $\Sigma\left(\frac{N}{\eta}\right) T$ represents the summation of traffic effects applied at different times of the day, throughout a year. Such a summation accounts for daily and yearly temperature variations. The Shell method uses six dally periods and twelve annual periods. The summation of traffic and temperature interaction results in an effective viscosity such that:

$$
s_{\text {bit, visc }}=\frac{3 \eta_{e f f}}{t_{w} N}
$$

For purposes of estimating the $s_{b 1 t, v i s c}$ for Indiana, $\eta_{\text {eff }}$ values associated with Chicago for a hardened 50 pen asphalt and a hardened 100 pen asphalt were selected from the Shell Pavement Design Manual (1978). Time of loading 
is based on mean highway speed in Indiana (Coree and White 1988) and is taken as the time for a truck to travel the diametric distance of circular loaded area determined for a $4500 \mathrm{lb}$ load and $100 \mathrm{ps} 1$ tire pressure. The resulting values of $S_{\text {bit, visc }}$ are:

\begin{tabular}{|c|c|c|}
\hline & $\begin{array}{c}\text { Hardened } \\
50 \text { pen } \\
\text { Asphalt } \\
\end{array}$ & $\begin{array}{l}\text { Hardened } \\
100 \text { pen } \\
\text { Asphalt }\end{array}$ \\
\hline$S_{\text {bit, } m i x}, \frac{N}{m^{2}}$ & 3.175 & 11.905 \\
\hline
\end{tabular}

Coree and White (1988) estimated that the mean asphalt penetration in Indiana was 64. Interpolating for this penetration gives an $s_{b 1 t, v i s c}$ of $8.572 \mathrm{~N} / \mathrm{m}^{2}$. An assumption is made that the $\mathrm{S}_{\text {bit, visc }}$ represents and therefore scales rutting damage. To determine an equivalent amount of traffic using the ATS when compared to 35 million ESAL, ten year traffic in Indiana; the $S_{\text {bit, visc }}$ corresponding to 35 million ESALs is entered into the equation. Time of loading equal to $5 \mathrm{mph}$ and a viscosity at a specific temperature is also entered into the equation. As a result, the number of axle loads (N) can be determined that would create the same rutting damage ( $s_{b i t, m i x}$ ) developed by 10 years of traffic.

Estimates can be made of the number of cycles of loading with the ATS using the above concept. Initial rutting tests planned with the ATS involve. placement of a three inch bituminous surface on a base concrete slab. Conduits in the concrete slab will provide heating to hold the bituminous surfacIng temperature constant. With a constant temperature only the bitumen viscosity at different temperatures needs to be determined. The following relation is used to estimate the recovered bitumen penetration (ASTM D5) at $20^{\circ} \mathrm{C}$. 


$$
\operatorname{Pen}_{\mathbf{r}}=0.65 \operatorname{Pen}_{1}
$$

Using this relation with a Pen ${ }_{1}$ of 64 results in a Pen ${ }_{r}$ of 41.6 . Two factors might affect the penetration of ATS test sections. First, the duration of any test is expected to be a few days to a few months. Second, a higher rate of hardening might be expected as a result of elevating the test section temperature. Because these factors might be off setting the above relation is considered to be reasonable. A simflar assumption for viscosity would be that the viscosity would double. The resulting penetration and viscosity data for an AC-20 asphalt are plotting on Figure 1. Estimates of the number of cycles of loading for the equivalent rutting damage $\left(S_{\text {bit, visc }}\right)$ are given for different temperatures:

\begin{tabular}{lrrrc}
$\begin{array}{c}\text { Temperature } \\
C\left(F^{\circ}\right)\end{array}$ & $\begin{array}{c}n \\
\text { poise }\end{array}$ & $N$ & $\begin{array}{c}\text { Days } \\
\text { of } \\
\text { Operation }\end{array}$ \\
\cline { 1 - 1 } $38(100)$ & & 10,500 & 41,853 & 7.3 \\
$60(140)$ & 4,000 & 15,944 & 2.8 \\
$82.2(180)$ & 850 & 3,388 & 0.6
\end{tabular}

In these estimates a loading time of $0.086 \mathrm{sec}$ was used. It is interesting that the decrease from highway speed to the ATS $5 \mathrm{mph}$ testing speed decreases the number of loading cycles by a factor of ten.

These estimates are considered to be approximate but do indicate that rutting damage can be developed with the ATS in a reasonable period of time. Load and tire pressure are two other factors that could be varied and factored Into the ATS tests to accentuate rutting damage.

\section{Design of Accelerated Testing Systems}

The primary function of the ATS is to apply up to a 20,000 pound load on 


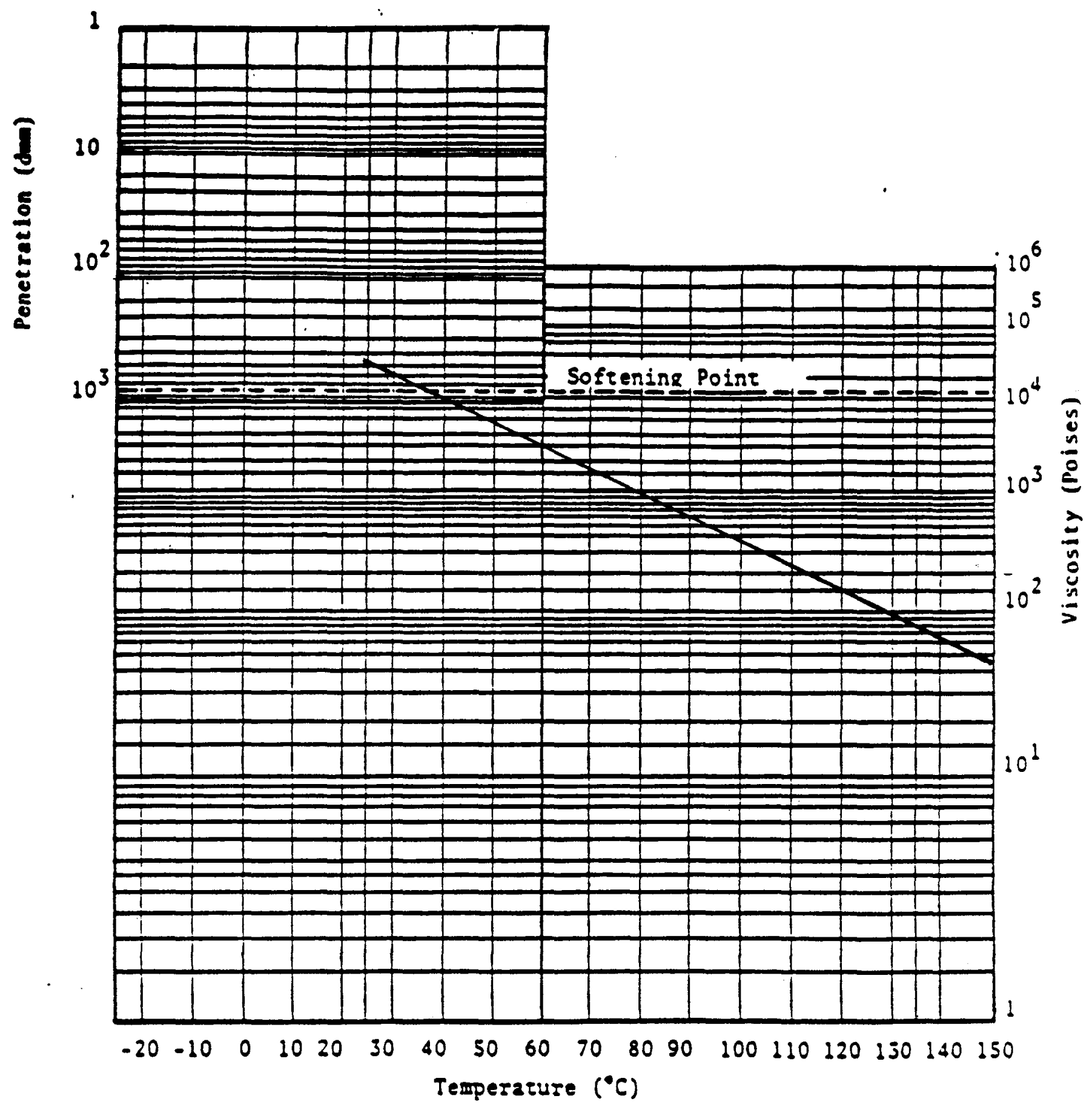

Figure 1.. Bitumen Test Data Chart. 
a wheel assembly as it moves across a section of test pavement. The proposed system is unique in that it uses mechanical linkages and springs to provide the loading force. Such a system is much 1 ighter than a system a 20,000 pound mass to generate the load. Since the loading device must move with the wheel assembly, a lighter assembly means the energy required to operate the system will be reduced. This is a major consideration because it will be run continuously. Use of a hydraulic system was considered, but maintenance and the possibility of contaminating the test pavement with hydraulic fluid could not be eliminated easily. A closed loop hydraulic would be expensive.

Reaction forces generated by the loading system are transmitted to the foundation using the structure shown in Figure 2. Figure 2 is a conceptual drawing of the ATS system. A pair of $\mathrm{S} 18 \times 54.7$ beams run horizontally across. the test pit with support structures at each end. The support structures are on rollers so the system can be moved to different lanes of the test pavement. Clamps are used at each end of the structure so that the reaction force of the wheel assembly does not lift the rollers off their tracks. Rollers with a capacity of 10,000 pounds each have been selected to support these loads. The largest stress occurs in the horizontal beams when the wheel assembly is centered between the end supports. Normal stress from bending was calculated for the case of a point load at the middle of a beam which is simply supported at each end. Using a load of $10,000 \mathrm{Ib} / \mathrm{beam}$, the stress ( $\sigma$ ) was found to be 17.5 ks1, which is well below the $36 \mathrm{ksi}$ yleld strength of structural steel (Beer and Johnston, 1981).

$$
\sigma=\frac{M c}{I}
$$



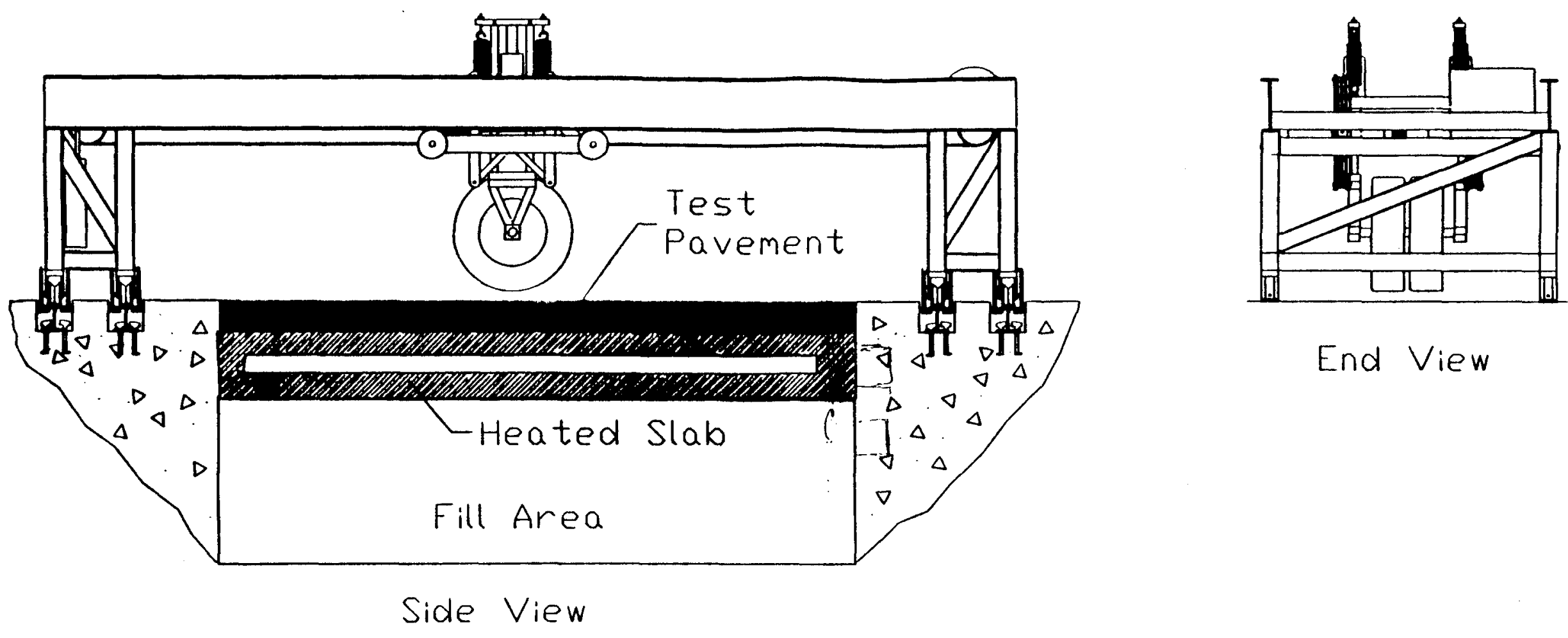

Figure 2. Accelerated Pavement Tester. 


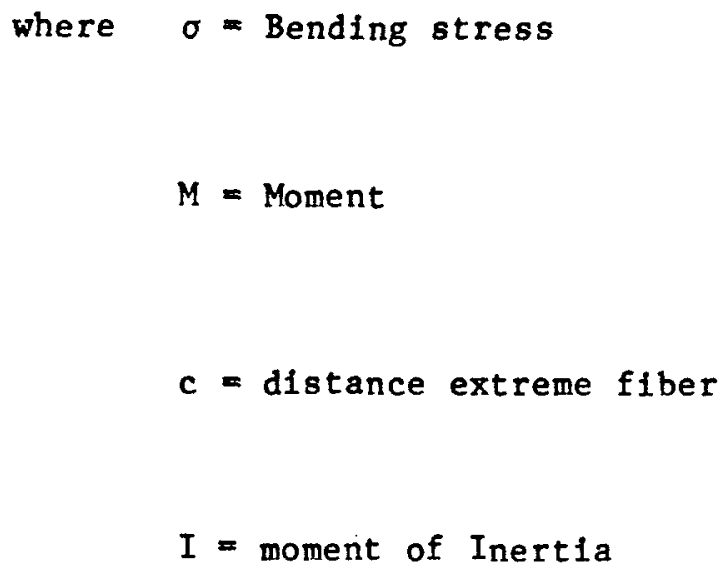

Since the beams will be continuously loaded and unloaded, fatigue must be considered. The stress will fluctuate between 0 and $17.5 \mathrm{ksi}$. This loading is 0.3 times the ultimate strength of $58 \mathrm{ksi}$, and therefore should not cause fatigue of the material (Beer and Johnston, 1981; Shigley and Mitche11, 1983). The maximum beam deflection can be calculated as 0.362 inches using:

$$
y_{\max }=\frac{P^{3}}{48 \mathrm{EI}}
$$

where $P=$ Point load

$$
\begin{aligned}
& L=\text { Length of beam } \\
& E=\text { Modulus of elasticity }
\end{aligned}
$$

$$
I=\text { Section Modulus }
$$

This deflection should not cause binding of the loading assembly as it moves along the beams. Since the end support provides some resistance to bending, these calculations based on simply supported ends are conservative. 
A constant vertical force is required on the wheel assembly as it travels across the test pavement. However, as the pavement deterforates, surface 1rregularities will cause vertical deflection of the wheel assembly. Two mechanisms that would maintain a constant force as they are deflected are belng considered (Jenuwine and Midha, 1990 and Nathan, 1985). Figure 3 shows a schematic the constant mechanism developed by Jenuwine and Mida (1990). Figure 4 shows how the mechanism can be implemented on the ATS. Identical mechanisms exert a force of 10,000 pounds on each end of the axle.

Before each pass of the wheel across the pavement, the wheel assembly must be lifted and positioned laterally. Lift will be provided by pneumatic cylinders acting on the constant force mechanism. The power required to complete the lift in 0.25 seconds is 73.5 hp using:

$$
\text { Power }=\frac{F d}{t}
$$

$$
\text { where } \begin{aligned}
F & =\text { Force } \\
d & =\text { distance } \\
t & =\text { time }
\end{aligned}
$$

Since lifting is not done continuously, a $5 \mathrm{hp}$ compressor operating during a 6.5 second overall cycle time will be capable of storing sufficient energy in an air tank for the left function. Counteracting the 20,000 pound force directly would require two 10 inch diameter cylinders operating at 125 psi. Use of a mechanical advantage to reduce cylinder diameter is heing considered. 


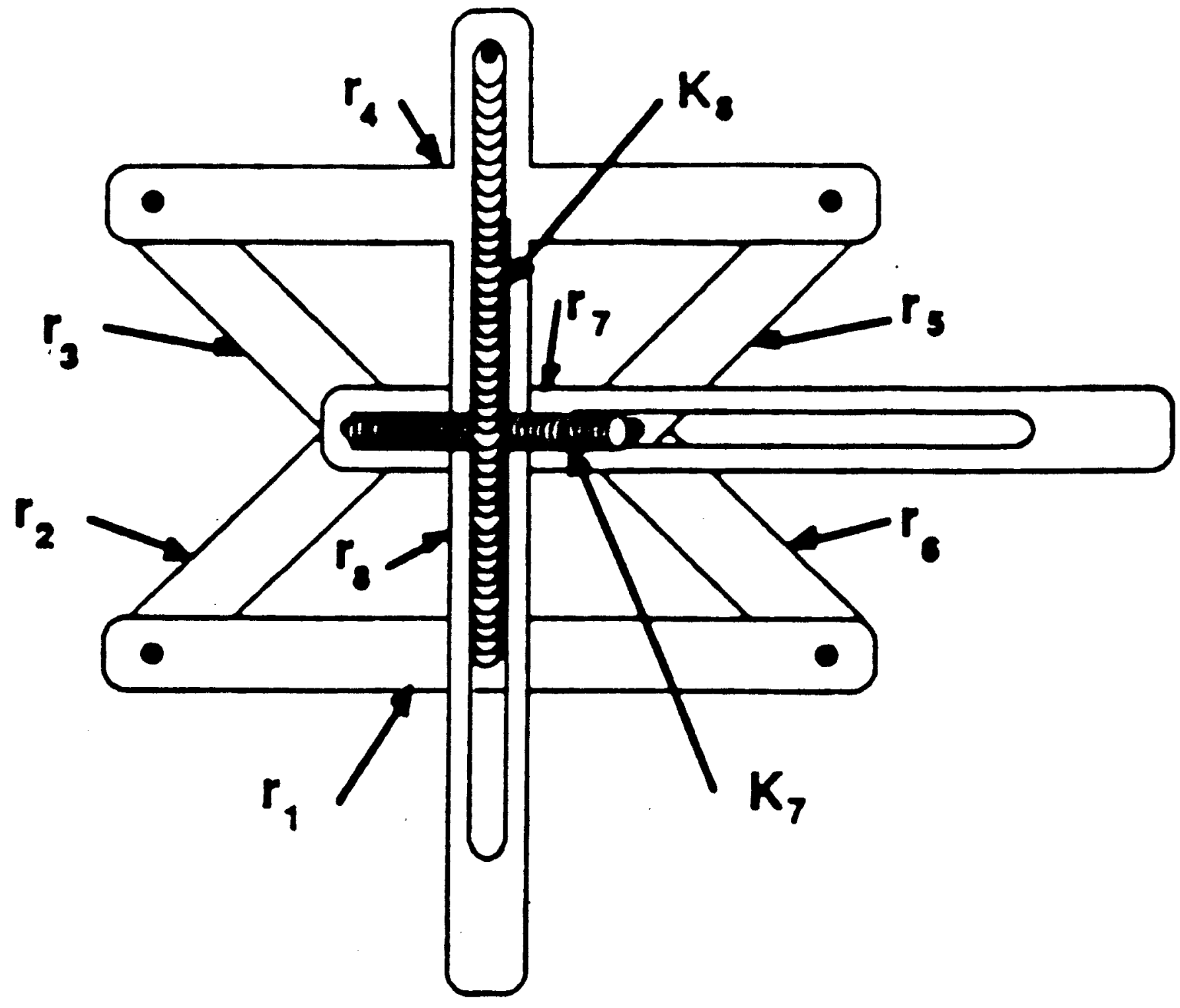

Figure 3. Constant Force Mechanism (Jenumine and Midha, 1990). 


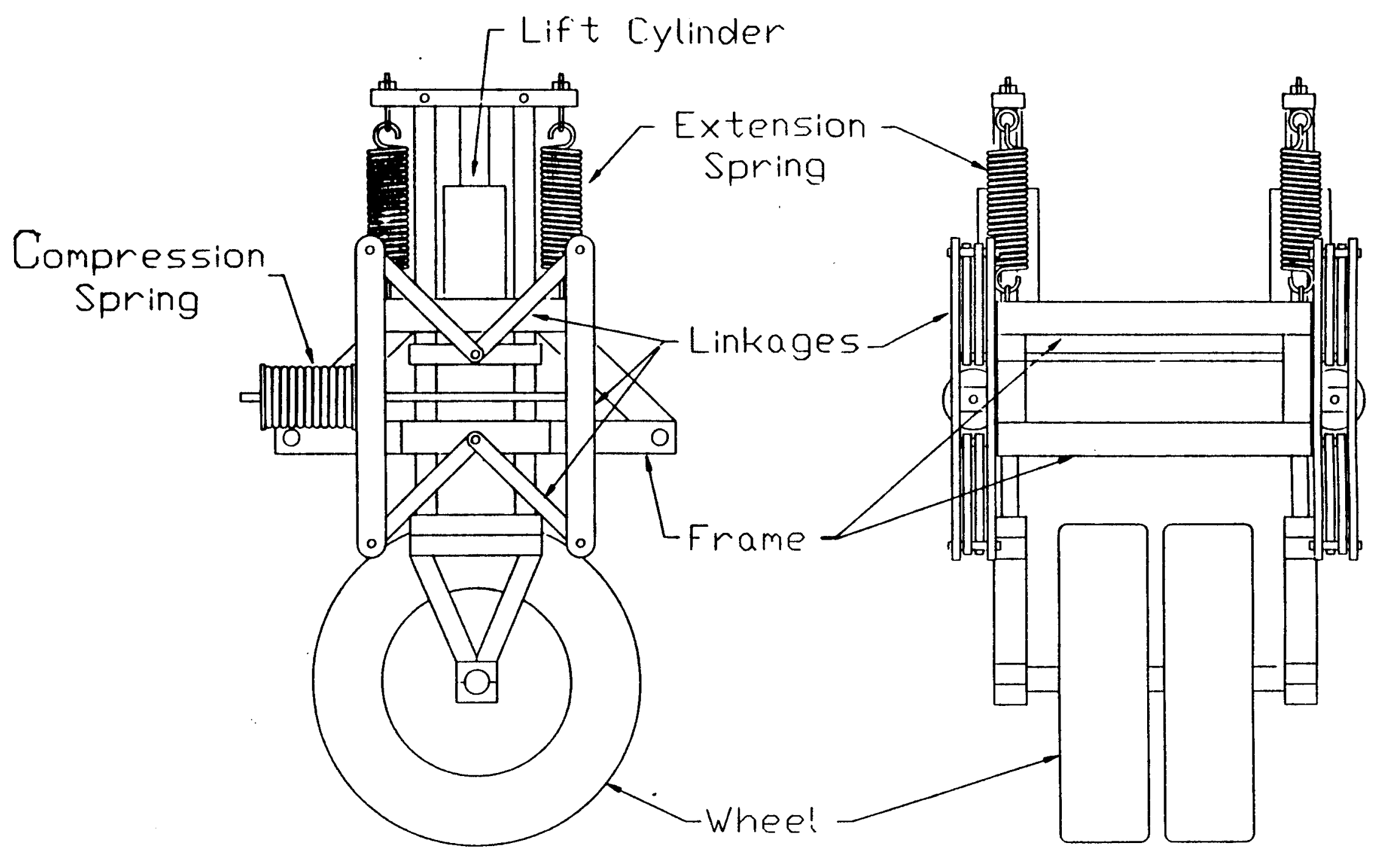

Figure 4. Constant Force Mechanism. 
Lateral positioning between cycles is necessary to simulate vehicle wander. This will be provided by an electrlc motor driving a palr of ball screws, as shown in Figure 5. The highest power requirement will occur when moving 2000 pounds (weight of the wheel assembly) a distance of 12 inches in one second. A two hp motor will be sufficient to provide this capability. The lateral drive system will be located on the moving portion of the ATs, so that its wiring can not be fixed. Power will be supplied through a cord reel suspended from the celling of the test facility.

Longitudinal motion of the wheel assembly along the test lane will be provided by a cable drive system which is powered by a $30 \mathrm{hp}, 480$ volt, 3 phase electric motor. A schematic of this system is shown in Figure 6 . The motor will be placed on one of the structure end supports along with the gear. box which connects the motor to the cable drum.

Sizing of the main drive system motor was based on rolling resistance of the tires on pavement, rolling resistance of the steel rollers on their ralls, and the acceleration required of the wheel assembly at the start of a pass. Tire rolling resistance was calculated to be 240 pounds using:

$$
R=f N
$$

\author{
where $R=$ Rolling Resistance \\ $f=$ Rolling resistance coefficient \\ $\mathrm{N}=$ Normal force
}




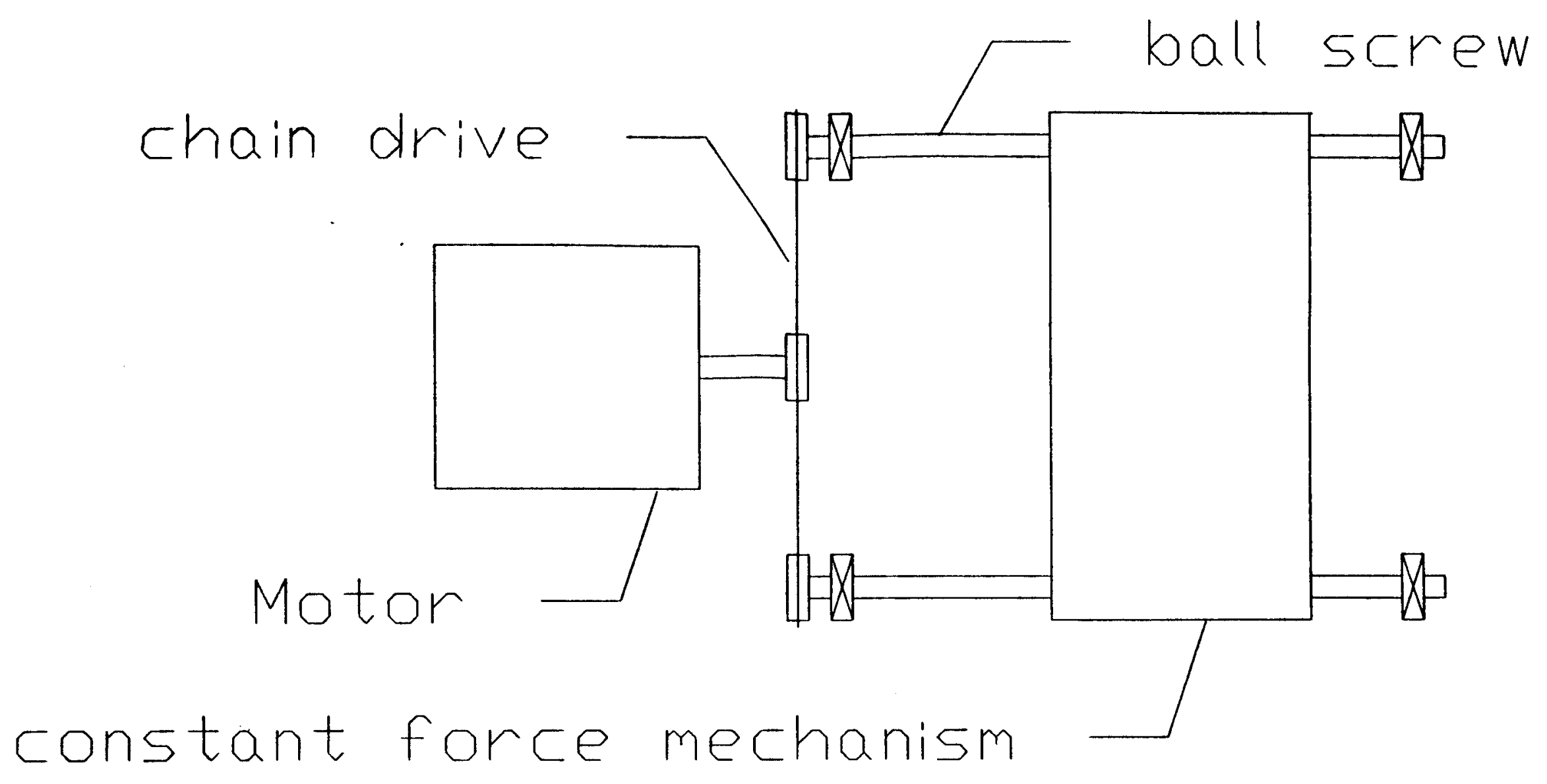

Figure 5. Lateral Positioning System. 


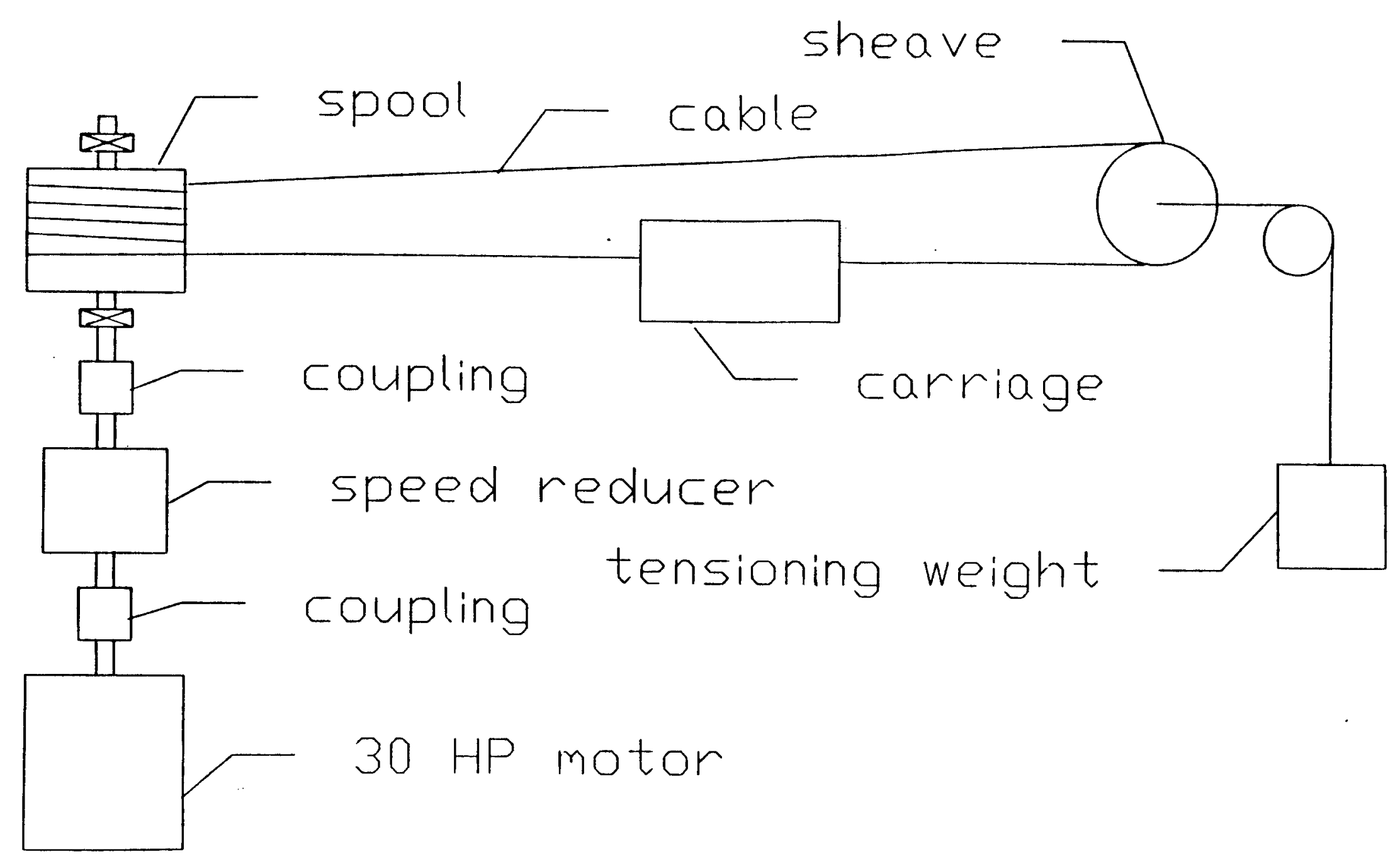

Figure 6. Transverse Drive System. 
with 0.012 for the coefflclent of rolling resistance (Wong, 1978). Rolling resistance of the steel rollers was calculated to be 200 pounds using a rolling resistance coefficient of 0.01 (Marks Standard Handbook for Mechanical Engineers, 1978). It is desired to accelerate the 3000 pound assembly to 5 mph in a distance of two feet. Assuming constant acceleration, a value of $13.4 \mathrm{ft} / \mathrm{sec} / \mathrm{sec}$ is calculated using:

$$
a=\frac{v^{2}}{2 s}
$$

where $a=$ acceleration

$$
v=\text { velocity }
$$

$s=$ distance

The required force (F) is 1700 pounds using:

$$
F=m a+R
$$

where $m=$ mass

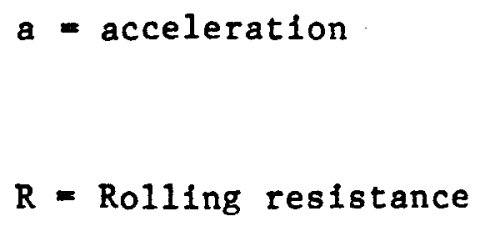

A conservative estimate of the power requirement can be found by multiplying this force by the steady state speed of $5 \mathrm{mph}$. The result is approximately 23 hp. Assuming 75 percent efflciency for the cable drive and gearbox, the power 
required at the motor is $30 \mathrm{hp}$.

A counter weight w111 be used to maintain tension in the drive cable. This counterwelght must provide a force twice the maximum force required to accelerate the wheel assembly. The counterwelght must therefore weigh 3400 pounds unless a mechanical advantage is used.

The entire operation of the ATS, as well as all data acquisition, will be controlled by a micro-computer. Two sixteen bit data acquisition boards w111 be used to interface with the motor controllers and all required sensors. Variable frequency controllers with reversing and soft start options will be used for both the main and lateral drive systems. Position of the system will be monitored with encoders. Limit switches will be used to shut down the system if the wheel assembly should exceed its normal operating zone, and a brake will be engaged if the motor controller cannot stop the assembly because of power failure. The above precautions should be sufficient to prevent a crash of the system.

The purpose of this design synopsis is to demonstrate that the ATS can be built using existing technology. An over all summary and itemized costs are given in Appendix A.

\section{Experfmental Design Planning}

First application of the ATS will be to study the minimum percent crushed aggregate requirements for bituminous mixtures. Meetings and discussions within INDOT and with industry resulted in the following factors and levels being identified as significant to determining the effect of crushed aggregate on rutting potential of bituminous mixtures. 
Factors

$\begin{array}{ll}\text { Maximum Aggregate Size (inch) } & 1 / 2,1,11 / 2 \\ \text { Coarse Crushed Aggregate (\%) } & 40,70,95 \\ \text { Bitumen Content ( } \%) & -0.5,0 \text { pt. +0.5 } \\ \text { Aggregate type } & \text { Grave1, Limestone, Slag } \\ \text { Uncrushed sand ( } \% \text { sand fraction) } & 0,50,100\end{array}$

In addition, it is recognized that $\mathrm{mix}$ design is a significant factor and would have to be addressed at a number of levels. The ATS will allow additional studies under controlled conditions which will produce data that can be added to a continuing data base on mix performance.

For purposes of simplicity and establishing a starting point the decision has been made to use one maximum aggregate size (one inch) and one surface thickness (three inches). As a result a full factorial of the experimental design would be a $3^{4}$ with 81 total sections. A one-third partial factorial would consist of 27 sections. Only one mix design would be included in this design. The cell structure of this design is shown in Figure 7 .

Operational testing of the ATS will be done with a standard bituminous mixture produced by a local plant. Subsequently, the first test sections will be the cells identified $X^{*}$ and will consist of essentially 100 percent crushed gravel satisfying INDOT specifications for a one inch maximum aggregate size bituminous mixture. As planned, at least three test sections can be installed at the same time for consecutive testing with the ATS. Since the bituminous mixture will be plant produced the logical process would be to calibrate the plant for one aggregate combination and gradation and then vary the bitumen 


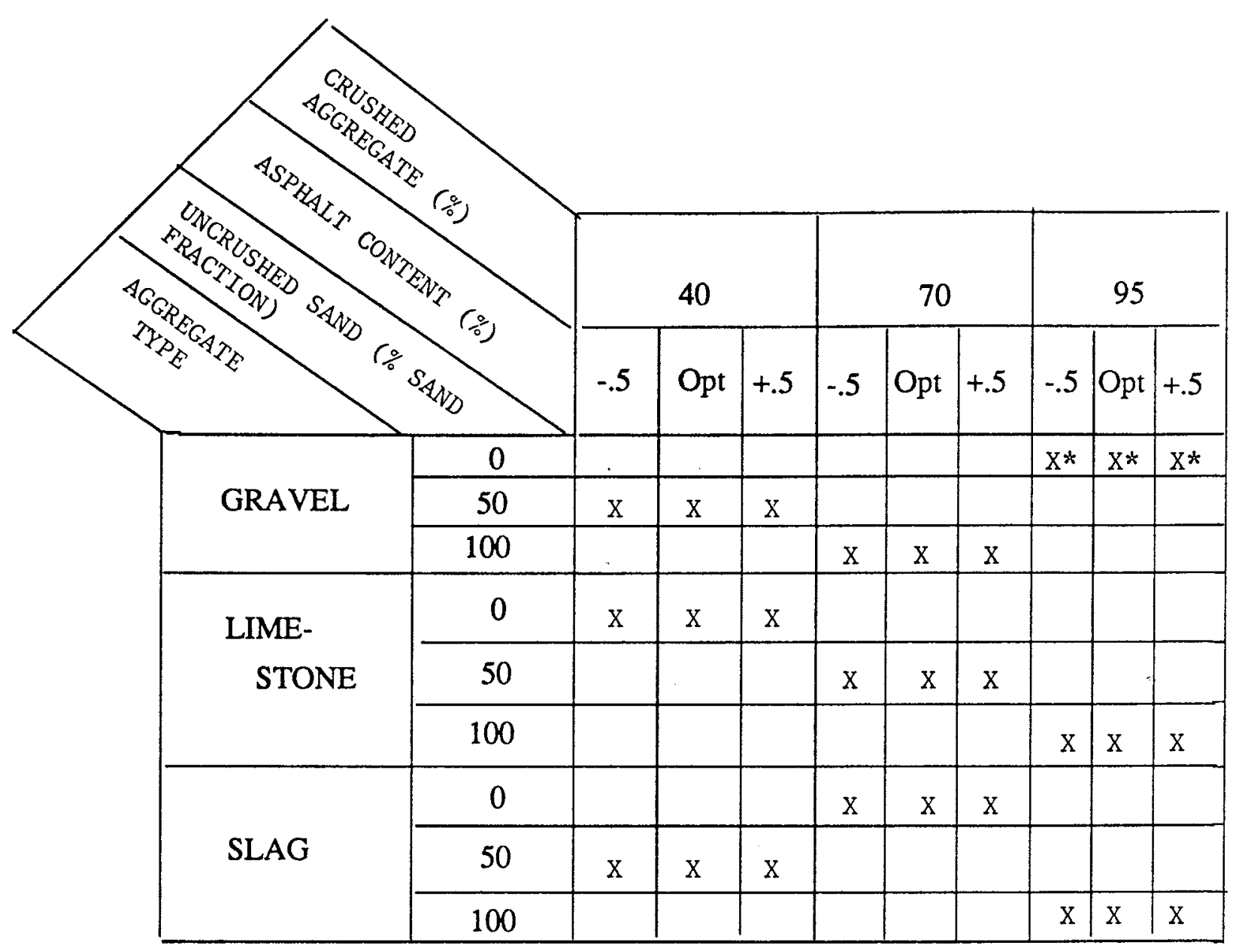

Figure 7. Preliminary Experimental Design. 
content. The result of this approach to producing the mixtures is to $11 \mathrm{mit}$ the statistical analysis to a study of the first order effects except for asphalt content.

The aggregate industry has supported the planning process and has solicited aggregate producer participation to supply aggregate for the study. A local contractor has indicated a willingness to cooperate in producing and placing the bituminous mixtures. Information is being acquired on consistency of asphalt supplies so that the same asphalt can be used for all test sections.

Summary

The major questions associated with Phase I of the HPR Part II project, "Determining Percent Crushed Aggregate Requirements in Bituminous Mixtures" have been answered. Operating characteristics of the ATS have been determined that would produce the accelerated structural and rutting damage. Estimates have also been made of the time to produce these distresses. In both cases the time is well within the one year criteria initial adopted.

A more detailed design of the ATS has been completed and costs have been estimated that appear to be close to the original estimate. Even with commerclal labor rates the costs are well below costs suggested by early review comments.

Significant planning has been accomplished on the experimental design. Th1s process ahs benefited from cooperative participation by INDOT and Purdue University staff as well as the aggregate industry. Broader interests have been indicated thru contractor participation. 
List of References

Akhter, G.F. and Witczak, M.W., "Sensitivity of Flexible Pavement to Bituminous Mix Properties", Transportation Research Record, N1034 pp 7079, Washington, D.C., 1985.

Autret, P, Baucheron de Bolssoudy, A., and Gramsammer, J.C., "The Circular Test Track of the 'Laboratoire Central des Ponts et Chaussees' (L.C.P.C.) Nantes - First Results", Sixth International Conference on the Structural Design of Asphalt Pavements, July 1987.

Barenberg, Ernest J., "The Behavior and Performance of Asphalt Pavements with Lime-Fly Ash-Aggregate Bases", Second International Conference on the Structural Design of Asphalt Pavements, Proceedings, August 1967.

Bazin. P., and Saunier, J.B., "Deformability, Fatigue and Healing Properties of Asphalt Mixes", Second International Conference on the Structural Design of Asphalt Pavements, Proceedings, August 1967.

Beer, F.P., and Johnston, E.R., Mechanics of Materials, McGraw-Hill Book Company, New York, New York, $198 \overline{1 .}$

Brown, S. F., and Pappin, J. W. "Use of a Pavement Test Facility for the Validation of Analytical Design Methods", Fifth International Conference on the Structural Design of Asphalt Pavements, Volume I Proceedings, August 1982 .

Claessen, A. I. M., Edwards, J. M., Sommer, P. and Uge, P., "Asphalt Pavement Design - The Shell Method," Fourth International Conference, Structural Design of Asphalt Pavements, Ann Arbor, Michigan, August 1977, pp 39-74.

Dempwolff, R., and Sommer, P., "Comparison Between Measured and Calculated Stresses and Strains in Flexible Road Structures", Third International Conference on the Structural Design of Asphalt Pavements, Volume I Proceedings, September 1972.

Eisenmann, J., and Hilmer, A., "Influence of Wheel Load and Inflation Pressure of the Rutting Effect at Asphalt-Pavements - Experiments and Theoretical Investigations", Sixth International Conference on the Structural Design of Asphalt Pavements, July 1987.

Eppensteiner, W., Gregir1, H., Hintsteiner, E., and Krzmien, R., "Assessment of Mineral Aggregates in B1tuminous Pavement Construction. The Relation Between Laboratory Tests and Performance in Practice. Part 2: Long Term Observations", Transportation and Road Research Lab, Report "108, 1979.

Ferreira, M. A., Servas, V. P., and Marais, C. P., "Accelerated Testing of Recycled Asphaltic Concrete", Prepared for the 62nd Annual Meeting of the Associated of Asphalt Paving Technologists, Reno, Nevada, February 
1987.

Freeme, C. R., Maree, J. H., and Viljoen, A., "Mechanistic Design of Asphalt Pavements and Verification Using the Heavy Vehicle Simulator", Fifth International Conference on the Structural Design of Asphalt Pavements, Volume I Proceedings, August 1982.

Gusfeldt, R. H., and Dempwolff, K. R., "Stress and Strain Measurements in Experimental Road Sections Under Controlled Loading Conditions,", Second International Conference on the Structural Design of Asphalt Pavements, Proceedings, August 1967.

Hicks, R. G., Albright, S., and Lundy, J. R., "Evaluation of Percentage Fracture and Gradation on Behavior of Asphalt Concrete and Aggregate Base", Executive Summary Highway Research Information Service, Report No: AR-RD-86-25A, December 1985.

Hofstra, A., and Klomp, A. J. G., "Permanent Deformation of Flexible Pavements Under Simulated Road Traffic Conditions", Third International Conference on the Structural Design of Asphalt Pavements, Volume I Proceedings, September 1972.

Hofstra, A., and Valkering, C. P., "The Modulus of Asphalt Layers at High Temperatures: Comparison of Laboratory Measurements Under Simulated Traffic Conditions with Theory", Third International Conference on the Structural Design of Asphalt Pavements, Volume I Proceedings, September 1972 .

Hugo, F., Servas, V. P., and Snyman, D. R. F., "Heavy Vehicle SimulatorAlded Validation of Pavement Behavior at Low Temperatures", Undated.

Jenuwine, J. G., and Midha, A., A Constant Force Generating Mechanism, U.S. Patent to be filed, 1990. Kadar, P., "Accelerated Full Scale TestIng of Heavy Duty Pavements - Experience with the Australian Accelerated Loading Facility (ALF)", Sixth International Conference on the Structural Design of Asphalt Pavements, July 1987.

Kingham, R. Ian, and Kallas, B. F., "Laboratory Fatigue and its Relationship to Pavement Performance", Third International Conference on the Structural Design of Asphalt Pavements, Volume I Proceedings, September 1972.

Klomp, A. L. G., and Niesman, Th. W., "Observed and Calculated Strains at Various Depths in Asphalt Pavements", Second International Conference on the Structural Design of Asphalt Pavements, Proceedings, August 1967.

Kraemer, P., "Production of a High-Graded Bituminous Subbase", Transportation and Road Research Lab., Volume 12, 1966.

Ledbetter, R. H., Ulery, H. H., Jr., and Ahlvin, R. G., "Traffic Tests of Alrfield Pavements for the Jumbo Jets", Third International Conference on the Structural Design of Asphalt Pavements, Volume I Proceedings, September 1972. 
Mahoney, Joe P., and Terrel, Ronald L., "Laboratory and Field Fatigue Characterization for Sulphur Extended Asphalt Paving Mixtures", Fifth International Conference on the Structural Design of Asphalt Pavements, Volume I Proceedings, August 1982.

Marks Standard Handbook for Mechanical Engineers, 8th edition, McGrawHil1 Book Company, 1978.

Maxwe11, A. A., Ahlvin, R. G., and Brown, D. N. "Controlled Tests of Mixed Loads of Flexible Pavements", International Conference on the Structural Design of Asphalt Pavements, August 1962.

Nathan, R. H., "A Constant Force Generation Mechanism", Journal of Mechanisms, Transmissions, and Automation 1n Design, Volume 107, December 1985.

Papazian, Hratch S., "The Response of Linear Viscoelastic Materlals in the Frequency Domain with Emphasis on Asphaltic Concrete", International Conference on the Structural Design of Asphalt Pavements, August 1962.

Paterson, W. D. C., "Deformations in Asphalt Concrete Wearing Course Caused by Traffic", Third International Conference on the Structural Design of Asphalt Pavements, Volume I Proceedings, September 1872.

Regan, G. L., "A Laboratory Study of Asphalt Concrete Mix Designs for High-Contact Pressure Alrcraft Traffic", Final Report, Waterways Fxperiment Station Geotechnical Laboratory, Report No. ESL-TR-85-66, July 1987.

Scazziga, I., "Verification of the Design Method for Asphalt Pavements in Switzerland", "Fifth International Conference on the Structural Design of Asphalt Pavements, Volume I Proceedings, August 1982.

Sharma, M. G., Kenis, W. J., Larson, T. D., and Gramling, W. L., "Evaluation of Flexible Pavement Design Methodology Based Upon Field Observations at PSU Test Track", Fourth International Conference - Structural Design of Asphalt Pavements, Volume I Proceedings, August 1977.

"She11 Pavement Design Manual", She11 Petroleum Company Limited, London, 1978.

Shigley, J. E., and Mitche11, L. D., Mechanical Engineering Design, McGraw-H111 Book Company, New York, New York, 1983.

van Vuuren, D. J., "Pavement Performance in the $\$ 12$ Road Experiment, an AASHO Satellite Test Road in South Africa", Third International Conference on the Structural Design of Asphalt Pavements, Volume I Proceedings, September 1972.

Viljoen, A. W., Freeme, C. R., Servas, V. P., and Rust, F. C., "Heavy Vehicle Simulator Aided Evaluation on Overlays on Pavements with Active Cracks", Sixth International Conference on the Structural Design of Asphalt Pavements, July 1987. 
Wong, J. Y., Theory of Ground Vehicles, John Wiley and Sons, New York, New York, 1978.

Yoder, E. J., and Witczak, M. W., "Principles of Pavement Design", 2nd Ed., John Wiley and Sons, New York, New York, 1975. 
Appendix A: Estimated Costs of Accelerated Testing System

The following cost estimate is based on a preliminary design of the accelerated testing system (ATS). Wherever possible, prices for stock components were taken from catalogs. Parts which must be fabricated have been developed far enough to estimate the amount of material required and the number of man-hours required for construction. Material costs were estimated at 60 cents per pound of steel required. Commercial labor costs have been estimated at $\$ 40$ per man-hour. However, alternate labor costs are also discussed. Total cost of the ATS is estimated to be $\$ 107,888$.

A breakdown by major subsystem is as follows:

$\begin{array}{lr}\text { Support Structure } & \$ 41,323 \\ \text { Main Drive System } & 15,769 \\ \text { Lateral Positioning System } & 1,910 \\ \text { Wheel Assembly } & 4,891 \\ \text { Constant Force Mechanism } & 14,496 \\ \text { Constant Force Mechanism Carriage } & 1,499 \\ \text { Controls and Data Acquisition } & 20,000 \\ \text { Assembly Labor (160 man hours) } & 8,000\end{array}$

$\$ 107,888$ Total

On a proportional basis the materials costs and commercial rate labor costs are: 


$\begin{array}{lr}\text { Total Cost } & \$ 107,888 \\ \text { Material Costs } & 36,000 \\ \text { Commercial Labor Costs } & 72,000\end{array}$

As noted above, the commercial hourly rate is $\$ 40$ per hour. Two alternative hourly rates are available within the Unfversity Shops. The Central Machine Shop hourly rate is $\$ 25$ per hour and the Mechanical Engineering Machine Shop hourly rate is $\$ 20$ per hour. If a 50 percent split of the work is taken between the Central Machine Shop and Mechanical Engineering Machine Shop the effective hourly rate would be $\$ 22.50$ per hour. As a result the labor costs for the ATS would be reduced to $\$ 40,500$ or a total cost of $\$ 76,500$. There are one or two other savings that could be realized but will not be applied at this time. 